\title{
S. BRUCE ARCHIBALD \& VLADIMIR N. MAKARKIN (2021) Early Eocene snakeflies (Raphidioptera) of western North America rom the Okanagan Highlands and Green River Formation. Zootaxa, 4951: 41-79.
}

The captions of Figure 2 and 9 should read as follows:

FIGURE 2. Wing venation of Megaraphidia antiquissima sp. nov., holotype RBCM P1555. A, right forewing, $\mathrm{B}$, left forewing; $\mathrm{C}$, right hind wing; $\mathrm{D}$, left hind wing. Scale bar $=3 \mathrm{~mm}$ (all to scale).

FIGURE 9. Wing venation of Megaraphidia hopkinsi sp. nov., holotype UWBM77544. A, right forewing; B, left forewing; C, right hind wing; D, left hind wing. Scale bar $=3 \mathrm{~mm}$ (all to scale).

In FIGURE 8A, portions of the image were duplicated by software error. The correct image of the specimen is as below:

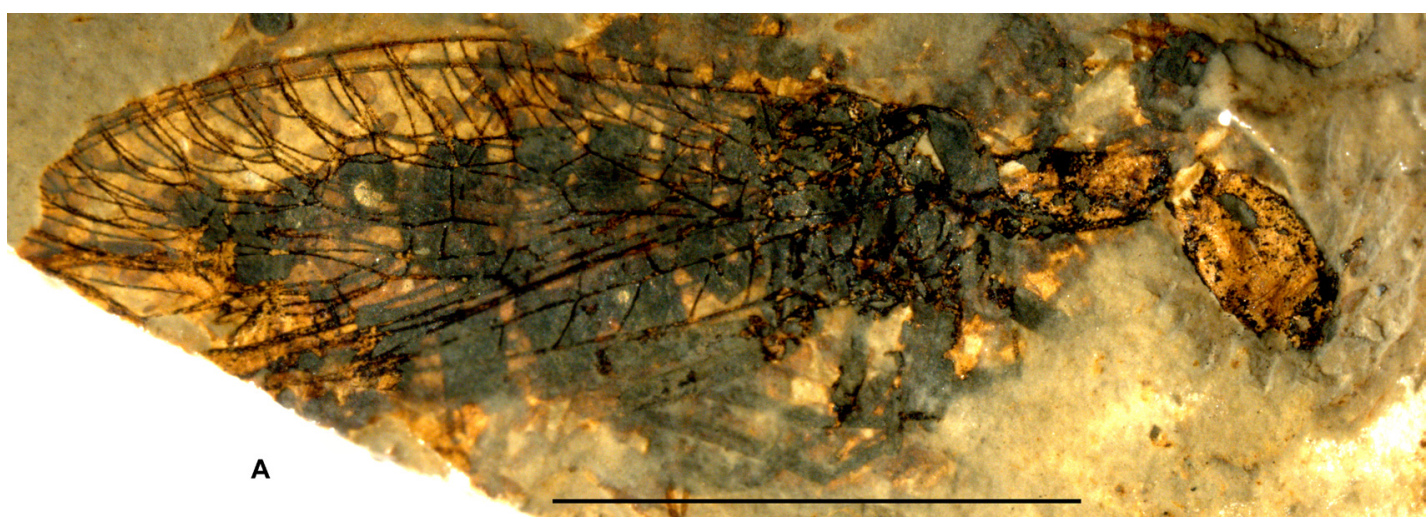

